16. Вылцан М.А. Победа колхозного строя и мероприятия партии и государства по улучшению жизни советского крестьянства (1932-1940) // Вопросы истории КПСС. 1968. № 6. С. 42-54.

17. Государственный архив Новейшей истории Ульяновской области (ГАНИ УО). Ф. 8. ОП. 1. Д. 119.

18. ГАНИ УО. Ф. 8. ОП. 3. Д. 233.

19. ГАНИ УО. Ф. 8. ОП. 3. Д. 230.

20. ГАНИ УО. Ф. 8. ОП. 5. Д. 293.

21. ГАНИ УО. Ф. 8. ОП. 6. Д. 147.

22. ГАНИ УО. Ф. 8. ОП. 5. Д. 2.
23. Хасянов О.Р. «...Их нужно выгнать из села вместе с их семьями...»: практика реализации Указа Президиума Верховного Совета СССР от 2 июня 1948 г. в Ульяновской области в документах государственных архивов. Ульяновск, 2015. 254 с.

24. ГАНИ УО. Ф. 8. ОП. 6. Д. 404.

25. ГАНИ УО. Ф. 8. ОП. 6. Д. 220.

26. ГАНИ УО. Ф. 8. ОП. 7. Д. 495.

27. Государственный архив Ульяновской области (ГАУО). Ф. Р-2520. Оп. 7. Д. 65.

28. ГАУО. Ф. Р-2520. ОП. 7. Д. 70.

\title{
EROSION WORK ETHIC OF THE SOVIET PEASANTRY IN THE POSTWAR DECADES (ON MATERIALS OF THE ULYANOVSK REGION)
}

(C) 2016

O.R. Khasyanov, candidate of historal sciences, head of the Chair of Philosophy and History

Ulyanovsk State Agricultural Academy named after P.A. Stolypin, Ulyanovsk (Russia)

L.N. Galimova, doctor of historal sciences, professor of the Chair of Humanitarian and Social Disciplines

Ulyanovsk Institute of Civil Aviation named after Chief Marshal of Aviation B.P. Bugaev, Ulyanovsk (Russia)

Abstract. Modern problems in the agricultural sector are rooted in the fact that for decades the state agricultural policy was characterized by neglect of the interests of the main producer, non-economic coercion to labour, alienation from the land and produced goods, infringement of social rights of the peasantry which inevitably led to urbanization, population migration from villages.

On the basis of the study of the scientific literature and archival documents which have been analysed for the first time, the complex process of destruction of the collective farmers's attitude to work in the public sector is explored. According to the author, the material difficulties of rural society in the war years led to the recovery in the agricultural society of previous forms of economic activity, namely the one-man operation in its stead. The victorious conclusion of the war led to the restoration of the pre-war state policy in the field of agriculture, but farmers continued to ignore social work. The author believes that public campaigns aimed at the restoration of collective farmers's labor discipline were unsuccessful because in the absence of material incentives the collective farmers were not ready for selfless labor in social production.

Keywords: economics, agricultural policy, farm, labor relations, work ethic, the peasantry, the agricultural artel, work ethic, value of work, the peasant ethics, and the efficiency of labor.

\section{УДК $947(571.53) 3$ \\ ДЕМОГРАФИЧЕСКИЕ ПРОБЛЕМЫ ИНДУСТРИАЛЬНЫХ ГОРОДОВ ИРКУТСКОЙ ОБЛАСТИ В 1990-Е ГОДЫ \\ (C) 2016 \\ Т.П. Урожаева, кандидат исторических наук, сотрудник лаборатории исторической демографии Иркутский государственньй университет, Иркутск (Россия)}

Аннотация. В статье автор анализирует проблемы демографического развития промышленных городов Приангарья в 1990-е гг. В частности, акцентируется внимание на негативных тенденциях в естественном и миграционном движении городского населения, которые, в свою очередь, привели к депопуляции. Распределение муниципальных образований Иркутской области по знаяению общего коэффициента смертности позволяет выделить лишь наиболее общие закономерности. Минимальный уровень общей смертности фиксировался в юго-восточных и центральных районах области, а также в большинетве крупных и средних городов. Наиболее высокие значения общего коэффициента смертности приходились на северные районы области и ряд сельских районов и моногородов центральной и восточной части области. Преимущественно, это депрессивные муниципальные образования, имеющие моноотраслевую экономику. По мнению автора, причины демографической нестабильности индустриальных городов во многом были заложены в советский период и были связаны с практикой привлечения населения и заселения районов нового промышленного освоения. Экономический кризис и обострение социальных проблем в 1990-е гг. серьезно осложнили демографическое развитие городского населения в регионе. Демографический кризис 1990-х гг. можно было заметно сгладить, если бы на уровне федерального нентра и региона принимались меры по прекращению устойчивой депопуляции населения. В условиях краха политической системы демографическая политика на долгие годы была отодвинута на второй план. В результате демографический кризис, который зародился еще в 1980-х гг., в полной мере проявился на уровне региона в первое постсоветское десятилетие.

Ключевые слова: городское население, моногорода, демографический кризис, коэффициент рождаемости и смертности, миграционная убыль населения, трудоспособное население, депопуляция, старение населения, демографическая политика, депрессивные муниципальные образования. 
Народонаселение любого региона изначально выступало как элемент производительных сил, фактор формирования материальных и духовных потребностей общества, потребитель благ и услуг. Вместе с тем в переходный период (1990-е гг.) регион Приангарья столкнулся с демографической проблемой, а точнее демографическим кризисом. Будучи одной из самых злободневных социально-экономических проблем постсоветского периода, кризис назревал еще с конца 1980-х гг. Целью написания статьи стал анализ проблем снижения рождаемости, роста смертности, заболеваемости, а также миграционной убыли населения из городов Иркутской области. В ходе проведения исследования были использованы материалы публикаций местных и региональных печатных изданий, а также статистические архивные данные и опубликованные материалы сборников.

Население Иркутской области долгое время формировалось в неразрывной связи с хозяйственным освоением территории. В послевоенный период были возведены города, вся жизнь которых строилась вокруг крупных предприятий. С 1959 по 1993 г. население Приангарья увеличилось на 864 тыс. чел. При этом центрами, вбирающими в себя практически весь экономический и людской потенциал, оставались индустриальные города: Ангарск, Братск, Байкаљьск, Железногорск-Илимский, Саянск, Усть-Илимск. Численность городского населения продолжала расти как за счет естественного прироста, так и миграционного притока.

В 1990 г. регион Приангарья вошел в полосу демографического кризиса: при сокращении рождаемости выросла и смертность. С 1993 г. в Иркутской области отмечалось устойчивое сокращение численности городского населения [1, с. 20]. Статистика отмечала самый настоящий демографический упадок. Если в 1985 г на 1 тыс. чел. населения прирост составил 9,5 чел., то в 1992 г. - 1,1 чел. В 1993 г. впервые в послевоенной истории области уровень смертности превысил уровень рождаемости. «В нынешних социально-экономических условиях в ближайшей перспективе невозможно решить задачу расширенного воспроизводства населения, - так анализировал ситуацию доктор географических наук, профессор Института географии СО РАН Mисевич. - Можно лишь добиться сокращения младенческой смертности за счет улучшения работы учреждений здравоохранения, отрегулировать миграционные процессы» [2, с. 2].

Значительно ухудшились параметры естественного движения населения. Снизились показатели рождаемости: если в среднем по области в 1993 г. рождаемость составила 84\% к уровню 1990 г., то в Ангарске этот показатель был равен 67, Шелехове - 75, Усть-Илимске $82 \%$. На уровне 90-97\% удерживалась рождаемость лишь в Саянске и Железногорске-Илимском [3, с. 2].

Во второй половине 1990-х гг. демографический бум пережил Шелехов, где число новорожденных в 1998 г. по сравнению с первым полугодием 1997 г., увеличилось соответственно на $47 \%$, а также Саянск и Свирск (на 20\%) [4, с. 5]. В таблице 1. представлены показатели рождаемости в индустриальных городах Приангарья: Ангарске, Братске и Саянске в период с 1989 по 1998 г.

В Саянске, учитывая сравнительно молодое население, показатели рождаемости были на порядок выше (особенно в 1989-1990 гг.). Однако в связи с замедлением темпов промышленного и гражданского строительства, население стабилизировалось, уровень жизни значительно снизился, и показатели рождаемости резко пошли вниз. Они почти сравнялись с показателями более обжитых городов Приангарья. Наиболее низкая рождаемость, в пересчете на каждую тысячу жителей, отмечалась в 1998-1999 гг. в Шелехове.

Таблица 1 - Рождаемость в городах Иркутской области в 1989-1998 гг. (на 1 тыс. чел. населения)*

\begin{tabular}{|l|r|r|r|r|r|r|r|r|r|}
\hline \multicolumn{1}{|c|}{ Годы } & 1989 & 1990 & 1992 & 1993 & 1994 & 1995 & 1996 & 1997 & 1998 \\
\hline Ангарск & 14,6 & 12,6 & 9,2 & 8,8 & 9,3 & 9,3 & 8,8 & 8,5 & 8,1 \\
\hline Братск & 16,3 & 14,2 & 11,5 & 9,8 & 9,9 & 9,7 & 9,3 & 8,6 & 8,8 \\
\hline Саянск & 21,0 & 16,7 & 12,2 & 12,0 & 11,1 & 9,6 & 9,0 & 8,5 & 9,4 \\
\hline Шелехов & 16,8 & 15,3 & 13,8 & 11,6 & 10,4 & 10,8 & 10,4 & 10,3 & 9,8 \\
\hline
\end{tabular}

С 1991 г. практически во всех возрастных группах женщин происходило падение рождаемости. Слабая тенденция роста отмечалась с 2000 г. у женщин 25-39 лет. Негативная тенденция: на волне нестабильности в стране с 1992 г. произошел резкий скачок рождаемости у девочек-подростков, возраст которых не превышал 15 лет. С 1991 г. в городских поселениях число семей, имеющих двух и более детей, постепенно сокращалось. С другой стороны, с 1996 г. в селах росло число многодетных семей (5 детей) и семей, имеющих одного ребенка [6, с. 4]. В таблице 2. приведены показатели естественного прироста (убыли) по трем индустриальным городам Приангарья.

Таблица 2 - Естественный прирост (убыль) населения в городах Иркутской области в 1989-1998 гг. (на 1 тыс. чел. населения)*

\begin{tabular}{|l|r|r|r|r|r|r|r|r|r|}
\hline Годы & 1989 & 1990 & 1992 & 1993 & 1994 & 1995 & 1996 & 1997 & 1998 \\
\hline Ангарск & $-5,9$ & $-3,1$ & $-0,9$ & $-4,0$ & $-4,2$ & $-4,1$ & $-3,9$ & $-3,1$ & $-3,3$ \\
\hline Братск & 9,0 & 6,1 & 3,0 & $-1,2$ & $-2,5$ & $-3,1$ & $-1,9$ & $-1,8$ & $-1,6$ \\
\hline Саянск & 16,5 & 13,4 & 5,9 & 5,1 & 3,5 & 1,5 & 1,6 & $-0,2$ & 0,8 \\
\hline
\end{tabular}

В Саянске в 1989-1996 гг. сохранялись положительные показатели динамики населения, однако в 1997 г. естественная убыль населения составила - 0,2. В 1998 г. показатель прироста населения немного увеличился и составил 0,8 на 1 тыс. чел. В том же году отметил свой первый юбилей (10 лет) коллектив Саянского роддома. Его открытие в ноябре 1988 г. стало важным событием социального значения, ведь прежде рожениц приходилось возить почти за 30 км - в переполненные палаты соседней Зимы, что не способствовало здоровью новорожденных. За десятилетие в Саянском роддоме увидели свет более 6 тыс. малышей. Интересно, что после некоторого затишья в 1998 г. в городе вновь наблюдался всплеск рождаемости - коэффициент ее вырос почти до 5 на 1 тыс. чел. населения. Только в октябре 1998 г. появились на свет более 50 новорожденных. Способствовали этому, вероятно, и такие зафиксированные местной статистикой факторы - уменьшилось число разводов, а браков, напротив, стало больше [8, с. 2].

С 1987 г. наблюдается резкое падение уровня жизни населения. Низкий материальный достаток подрывал основы семьи. Это привело к снижению числа заклю-- 
чаемых браков и росту количества разводов. Особенно это стало заметно проявляться с 1992 г. Уже в 2002 г. в городах на каждый заключенный брак приходился один развод, в то время как в 1987 г. процент разводов относительно браков составлял только $43 \%$ [9, с. 2].

На территории Приангарья печально отличился г. Бодайбо, где распалось семей в полтора раза больше, чем было создано за 1999 г. Был заключен брак 40 пар молодоженов, а 61 семейная пара потерпела «кораблекрушение». Работникам ЗАГСов Бодайбо и Шелехова в 1999 г. пришлось чаще фиксировать печальное завершение брачного союза, чем полное надежд его создание. В противовес северянам и шелеховцам Свирск можно было по праву считать «заповедником семейной стабильности»: в 2000 г. 237 бракосочетаний и только 29 расставшихся пар. [10, с. 2$]$.

Распределение муниципальных образований Иркутской области по значению обциего коэффициента смертности позволяет выделить лишь наиболее общие закономерности. Минимальный уровень общей смертности фиксировался в юго-восточных и центральных районах области, а также в большинстве-крупных и средних городов. Наиболее высокие значения общего коэффициента смертности приходились на северные районы области и ряд сельских районов и моногородов центральной и восточной части области. Преимущественно это депрессивные муниципальные образования, имеющие моноотраслевую экономику.

В начале 1990-х гг. имел место незначительный разброс показателей смертности: от четырех случаев на 1 тыс. чел. в Саянске до шести - в Усть-Илимске. В 1994 г. уровень смертности поднялся во всех без исключения городах Приангарья. По его росту относительно 1993 г. первенство держал ЖелезногорскИлимский $-112 \%$. Между тем превышение рождаемости над смертностью за этот период было отмечено только в двух городах - Саянске (на 6,7\%) и Байкальске (на 8,9\%) [11, с. 41].

Еще в конще 1980-х - начале 1990-х гг. демографические процессы в относительно молодых городах Приангарья (Саянске, Байкальске, Усть-Илимске, УстьКуте, Шелехове, Железногорске-Илимском) отличались от аналогичных процессов в давно сложившихся городах (Тайшете, Нижнеудинске, Черемхово, УсольеСибирском и др.). В них была ниже демографическая нагрузка на трудоспособное население; низкие показатели смертности даже при начавшемся снижении рождаемости пока обеспечивали естественный прирост населения из-за сравнительно молодой возрастной структуры. Однако в последующем стали нарастать признаки старения населения «сверху» (за счет постепенного сокращения рождаемости) и «снизу» (с увеличением смертности лиц старшего возраста).

«Пик молодости» исследованных городов был уже пройден, их население постепенно подвергалось демографическому старению. Относительно молодыми к концу 1990-х гг. оставались жители Саянска и УстьИлимска, пенсионеров среди них насчитывалось соответственно 15 и 17\%. Из горожан, проживающих в Свирске более четверти (26-28\%) являлись лицами пенсионного возраста [12, с. 2-3].

Старение населения порождало новые требования к социальному обеспечению и медицинскому обслуживанию пожилых людей. Увеличение их доли на фоне сокращающейся численности экономически активного населения приводило к росту демографической нагрузки, создавало дополнительные трудности в их пенсионном обеспечении. Усиливались проблемы одиночества пожилых и старых людей, росла их отчужденность от более молодых поколений.

Со второй половины 1990-х гг. началось сокращение численности населения Саянска. Только в 1997 г. число горожан уменьшилось более чем на 0,5 тыс. человек - в основном за счет миграции, которая, в свою очередь, была напрямую связана с проблемами в работе градообразующего предприятия «Саянскхимпром». Наблюдалась и другая настораживающая тенденция: если прежде в городе рождалось больше, чем умирало, то в 1997 г. смертность впервые взяла верх - с разницей в 17 чел. Однако, после некоторого затишья в городе вновь наблюдался подъем рождаемости - коэффициент ее вырос почти до пяти на 1 тыс. чел. населения. Только в октябре 1998 г. появилось на свет более полусотни детей $[13$, с. 2-3]. Во многом этому способствовало уменьшение числа разводов, а зарегистрированных браков, напротив, стало больше.

В другом городе Иркутско-Черемховского промышленного района - Ангарске, основу населения изначально составляли его строители, приехавшие из разных регионов страны. Город нефтехимиков по количеству жителей занимал третье место в области после Иркутска и Братска. Трудоспособное население составляло примерно $63 \%$, из них около $40 \%$ работало в промышленной сфере. В 1990-е гг. процент детского населения несколько сократился, что было обусловлено невысоким уровнем рождаемости. Многие молодые семьи не спешили обзаводиться детьми. К этому решению приводила сложная социально-экономическая обстановка в городе: увеличение безработицы, задержки с выплатой заработной платы, удорожание содержания детей $[14$, с. 2]. Вместе с тем, начиная с 1999 г. наблюдалось некоторое повышение рождаемости - в детородный возраст вступало многочисленное поколение, родившихся после 1983 г. Этот период продлился лишь несколько лет.

Вместе с тем, город «старел»- средний возраст ангарчан к 1998 г. превысил 35 лет. Увеличивалось число пенсионеров. Миграционный отток был связан с отъездом молодежи. В анкетах молодые люди называли основные причины отъезда: в городе не было перспектив для получения жилья и хорошей работы. Прибывших в Ангарск на постоянное место жительства было меньше, чем покинувших город. К примеру, в 1999 г. приехавших сюда оказалось почти на тысячу человек меньше, чем годом ранее. Рождаемость падала, а смертность увеличивалась: в 1999 г. родилось чуть более двух тысяч человек, а умерло более 3,6 тыс. чел. [15, с. 3]. К 2000 г. население города настолько уменьшилось, что его численность впервые за многие годы стала меньше 250 тыс. чел.

Население Шелехова с середины $1960-x$ гг. увеличивалось за счет более высокого, по сравнению со среднеобластным уровнем, естественного прироста. При этом положительная демографическая динамика была устойчивой, и ее не смог поколебать даже кризис 1990-х гг. Во многом это можно было объяснить стабильной работой градообразующего предприятия и устойчивым функционированием городского 
хозяйства. Население в 1992 г. составило 49,3 тыс. чел, затем наблюдался некоторый рост, и в 1998 г. оно составило 53,4 тыс. чел. Однако в 1998-2000 гг. наблюдался значительный миграционный отток, и население уменьшилось до 47,5 тыс. чел. в 2002 г. [16, с. 2]. Тем самым Шелехов из разряда среднего города перешел в категорию малых городов Приангарья.

До начала кризиса 1990-х гг. для Байкальска был характерен рост населения. В 1970-е гг. темпы увеличения количества жителей были довольно внушительными, что объясняется прибытием рабочих и квалифицированных специалистов с разных регионов страны. С начала 1980-х гг. рост населения потерял свои былые темпы $(0,7 \%$ в год), хотя естественный прирост оставался довольно высоким. Демографический кризис, обострившийся в конце 1980-х Гг., достиг Байкальска лишь в 1994 г. Что касается возрастной структуры города, то она вплоть до 1996 г. являлась прогрессивной по сравнению со среднерегиональным уровнем. Однако, несмотря на сохраняющуюея возрастную структуру, население Байкальска постепенно старело. Во второй половине 1990-х гг. произошло сокращение естественного прироста. Количество прибывших в Байкальск превышало число уехавших (показатель миграционного прироста в 1994 г. составил 330 чел.) [17, c. 3]. Начиная с 1999 г. население города етало сильно уменьшаться, главным образом по причине отъезда наиболее активной части горожан из-за неопределенности в судьбе градообразующего предприятия.

В городах Среднего Приангарья (Братске, УстьИлимске, Железногорске-Илимском) в 1990-е гг. также сложилась неблагоприятная демографическая ситуа ция. Численность населения Братска в 1991 г. впервње стала уменьшаться, что произошло из-за возрастающего отъезда жителей из города, а также по причине снижения естественного прироста. В ноябре 1994 г. в Братске проживало 282 тыс. чел., хотя еще в 1980-е гг. город уверенно шел к трехсоттысячному рубежу. Изменение условий жизни, в связи с начавшимся экономическим кризисом, заставило многих горожан поменять прописку. Вместе с тем, только в 1994 г. братскую прописку получило около семи тысяч человек. Выехало больше - на 1,1 тыс. чел. [18, с. 2].

Еще в конце 1980-х гг. население города романтиков стало стремительно стареть: в 1995 г. каждый пятый братчанин достиг пенсионного возраста (50-55 лет) [19, с. 12-13]. Работоспособное население предпочитало покидать город, оставляя пожилых жителей. Так, Братск вышел на первое место в области по количеству пенсионеров: каждый четвертый житель города в 1999 г. имел пенсионное удостоверение. Число неработающих пенсионеров активно росло, и к середине 1999 г. их было уже более 44 тыс. чел. [20, с. 2].

С 1999 г. в Братске наблюдался рост рождаемости. Только в первом полугодии этого года на свет появилось более 1 тыс. детей, что на $6 \%$ было больше, чем в 1998 г. Однако смертность в городе по-прежнему превышала рождаемость. Одновременно с этим возрос отток населения. В результате город терял человеческий потенциал: в 2000 г. здесь проживало чуть более 270 тыс. чел., хотя в начале 1990-х гг. эта цифра превышала 282 тыс. чел. [21, с. 3]. С 1993 по 2000 г. наблюдалось ежегодное сокращение населения на 0,5-1,5 тыс. чел. Естественная убыль населения не могла быть компенсирована миграционным приростом.
Если в Братске с 1990 по 1998 г. население сокращалось, а в 1999 г. произошел его небольшой рост, то в Усть-Илимске наоборот в начале рассматриваемого периода наблюдался миграционный прирост, а затем последовал спад. В Железногорске-Илимском население стабильно росло первую половину 1990-х гг. и столь же стабильно сокращалось в 1996-1999 гг. В УстьИлимске рост населения продолжился до 1992 г., в Братске в этом году он стабилизировался. В 1993 г. население Братска не изменилось, а в Усть-Илимске началось его сокращение. Дольше всего благополучная демографическая ситуация продержалась в Железногорске-Илимском. В городе население росло до 1996 г. Максимальное количество жителей насчитывалось в 1997 г. - 33,5 тыс. чел. [22, с. 31-32]. Затем эта цифра стала уменьшаться, т.к. началась естественная убыль населения и отрицательные миграционные процессы.

В целом, в Среднем Приангарье с 1991 по 2000 гг. численность городского населения сократилась на 1,9\%, в том числе в Усть-Илимске на 11,2\%, в Железногорске - на 2,2\%, а Братске напротив выросла - на 1,7\% [23, c. 2]. Таким образом, к концу 1990-х гг. самая негативная демографическая картина сложилась в УстьИлимске. Она была обусловлена крайне неблагополучной социально-экономической ситуацией в городе.

С начала 1990-х гг. произошел качественный скачок в росте смертности и заболеваемости, падении рождаемости, снижении продолжительности жизни населения Усть-Илимска. Кроме того, одним из факторов снижения рождаемости стал переход части сельского населения в категорию городского [24, с. 3]. В городе большой проблемой оставался жилищный вопрос. Семейные пары из-за отсутствия жилья, стабильной заработной платы - или вовсе не стремились заводить детей или ограничивались одним ребенком.

Население Усть-Илимска продолжало стареть. В 1999 г. в городе насчитывалось более 21 тыс. пенсионеров, причем число пожилых людей ежегодно увеличивалось в среднем на одну тысячу. Всего за пять лет (с 1994 по 1999 г.) количество пенсионеров выросло с 16,5 тыс. до более 21 тыс. чел. Средний возраст населения города на рубеже веков составил 34 года. Еще в 1994 г. этот показатель равнялся 28. В 1999 г. из всего населения на долю трудоспособного возраста приходилось $61 \%$, младше трудоспособного возраста - $21 \%$, старше - всего $18 \%$ [25, с. 2]. Более трети трудоспособного населения города работало в сфере промышленности.

В целом, Усть-Илимск отражал общую тенденцию к снижению численности городского населения Иркутской области. В основном это было связано с миграцией молодёжи в более развитые в экономическом плане города области и другие субъекты РФ. Даже не смотря на высокий процент рождаемости, численность населения продолжала неуклонно сокращаться. Депопуляционные процессы в индустриальных городах региона стали очевидным фактом, и не стоило строить иллюзий по поводу скорого изменения к лучшему. Городским сообществам предстояло приспосабливаться К новым реалиям и самостоятельно искать ответ на вызовы времени. В таблице 3. представлены показатели динамики численности населения городов Приангарья в период между переписями населения: 1989 и 2002 гг. 
Таблица 3 - Численность населения индустриальных городов Иркутской области в 1989-2002 гг.*

\begin{tabular}{|l|r|r|r|r|}
\hline \multirow{2}{*}{ Города } & \multicolumn{4}{|c|}{ Численность населения, тыс. чел. } \\
\cline { 2 - 5 } & 1989 г. & 1992 г. & 1998 г. & 2002 г. \\
\hline Ангарск & 265,8 & 268,8 & 267,0 & 247,1 \\
\hline Байкальск & 16,4 & 16,7 & 17,2 & 15,7 \\
\hline Братск & 255,7 & 259,3 & 253,6 & 259,3 \\
\hline $\begin{array}{l}\text { Железногорск- } \\
\text { Илимский }\end{array}$ & 32,3 & 32,8 & 33,2 & 29,0 \\
\hline Саянск & 38,2 & 45,3 & 46,7 & 43,5 \\
\hline Усть-Илимск & 109,3 & 113,5 & 108,3 & 100,6 \\
\hline Шелехов & 47,7 & 49,3 & 53,4 & 47,5 \\
\hline
\end{tabular}

* Составлено по: [22, с. 31-32]

Демографический кризис 1990-х гг. можно было заметно сгладить, если бы на уровне федерального центра и региона принимались меры по прекращению устойчивой депопуляции населения. Во-первых, необходима была грамотно разработанная демографическая политика, предусматривавшая долгосрочные льготы и привилегии матерям, что позволило бы увеличить рождаемость. Во-вторых, для уменьшения уровня смертности нужно было повысить качество медицинского обслуживания, проводить пропаганду здорового образа жизни, улучшать условия труда (для сокращения травматизма на производстве). В-третьих, выходом из ситуации старения населения могло быть привлечение для постоянного проживания молодого трудоспособного населения.

Все эти меры могли бы не допустить глубокого демографического кризиса в регионе, но стоит учитывать и сложную социально-экономическую и политическую обстановку в стране, которая развернулась с конца 1980-х гг. В условиях краха политической системы демографическая политика на долгие годы была отодвинута на второй план. В результате демографический кризис, который зародился еще в 1980-х гг., в полной мере проявился на уровне региона в первое постсоветское десятилетие.

\section{СПИСОК ЛИТЕРАТУРЫ:}

1. Численность наличного и постоянного населения по городам, рабочим поселкам и районам Иркутской области на 1 января 1994 года и среднегодовая за 1993 год. Иркутск, 1994. С. 20.

2. Леньшина И. «Русский крест» над Иркутской областью: Показатели рождаемости и смертности // СМномер один. 1998. - 31 марта. С. 2.

3. Филиппова В. Время жить иль время умирать // Восточно-Сибирская правда. 1993. - 23 июня. С. 2.

4. Винокуров М. Население Иркутской области и трудовые ресурсы // Экономика. Право. Менеджмент. 1999. - 13-19 октября. № 39. С. 5.
5. Естественное движение населения в городах Иркутской области в 1990-2000 гг. Иркутск, 1991-2001. C. 34-51.

6. Филиппова В. «Хорошо, что все же нас мама родила!»: Стат. данные естественного прироста населения Иркутской области // Восточно-Сибирская правда. 1996. - 28 сентября. С. 4.

7. Архив Иркутского областного комитета государственной статистики. Данные о естественном движении городов области. Динамические ряды № 08-03-09.

8. Ильина Н. В Саянске демографический подъем // Приокская правда. 1998. - 10 ноября. С. 2.

9. Филиппова В. Одна возлюбленная пара: О браках и разводах в Иркутской области // Восточно-Сибирская правда. 1996. - 28 мая. С. 2.

10. Овсянникова И. Слабеют узы Гименея или Где найти спутника жизни? // Восточно-Сибирская правда. 2001. - 17 июля. С. 2.

11. Основные итоги микропереписи населения в 1994 году. Иркутск, 1995. С. 41.

12. Смирнова Е. Иркутская область неотвратимо стареет: О демографической ситуации в Иркутской области // СМ-номер один. 1998. -15 января. С. 2-3.

13. Соловьев Ю. Беби-бум в Саянске // Саянские зори. 1998. - 10 ноября. С. 2.

14. Кризис бьет по рождаемости // ВосточноСибирская правда. 1999. - 20 марта. С. 2.

15. Стареет город молодой // Время. 2000. - 28 сентября. С. 3.

16. Овсянникова И. Приангарье теряет жителей // осточно-Сибирская правда. 2002. - 5 марта. С. 2.

17. Суходолов А. Население Байкальска: демографические и социальные аспекты (1980-1995 гг.) // Байкальский целлюлозник. 1996. - 17 сентября. С. 3.

18. Братчан всё меньше // Знамя. 1994. 29 ноября. C. 2 .

19. Численность наличного и постоянного населения по городам, рабочим поселкам и районам Иркутской области на 1 января 1995. Иркутск, 1995. С. 12-13.

20. Монахов В. Прирастаем стариками // ВосточноСибирская правда. 1999. - 8 июня. С. 2.

21. Монахов В. Братск продолжает стареть // Восточно-Сибирская правда. 2000. - 1 августа. С. 3.

22. Ретроспективная численность населения по городам и районам Иркутской области в 1989-2002 гг. Статистический сборник. Иркутск, 2006. С. 31-32.

23. Стефанович Л. Сколько нас сегодня? // Восточно-Сибирская правда. 1998. - 23 декабря. С. 2.

24. Родькина Е. СТатистика знает всё // УстьИлимская правда. $1998-25$ июля. С. 3.

25. Стареем медленно, но верно // Усть-Илимская правда. 2000. - 4 октября. С. 2.

\section{DEMOGRAPHIC PROBLEMS OF THE INDUSTRIAL CITIES OF IRKUTSK REGION IN THE 1990S}

(C) 2016

T.P. Urozhaeva, candidate of historal sciences, researcher of the Laboratory of Historical Demography Irkutsk State University, Irkutsk (Russia)

Abstract. The author analyzes the problems of demographic development of industrial cities of the Angara area (Priangarye) in the 1990s. In particular, it focuses on the negative trends in the natural movement and migration of the urban population, which, in turn, led to depopulation. Distribution of municipal formations of the Irkutsk region in the total value of the mortality rate allows you to detect only the most general trends. The minimum level of total mortality was rec- 
orded in the south-eastern and central parts of the region, as well as in most large and medium cities. The highest values of total mortality rates were obseryed in the northern areas of the region and a number of rural and single-industry towns in central and eastern part of the region. Mostly, it's economically depressed municipalities with single-industry economy. According to the author, the causes of demographic instability in many industrial cities were laid during the Soviet period and were associated with the practice of attracting population and populating areas of new industrial development. The economic crisis and the aggravation of social problems in the 1990s seriously complicated demographic development of the urban population in the region. The demographic crisis of the 1990 s could have been significantly smoothed over, if the federal and regional authorities had taken steps to stop the steady depopulation. In the context of the collapse of the political system demographic policy for many years had been pushed into the background. As a result, the demographic crisis, which takes root in the 1980s, fully manifested itself at the regional level in the first post-soviet decade.

Keywords: urban population, towns, demographic crisis, fertility and mortality, migration, population decline, working-age population, depopulation, population aging, population policy, depressed municipality.

УДК 392.1

\section{ПЕРВЫЙ ГОД ЖИЗНИ РЕБЕНКА В АРМЯНСКОЙ СЕМЬЕ (НА ПРИМЕРЕ Г. САМАРА)} (C) 2016

Л.А. Агаджанян, старший преподаватель кафедры философии, истории и теории мировой культуры Самарский государственный социально-педагогический университет, Самара (Россия)

Аннотация. Тема детства является одной из значимых и интересных в российской и зарубежной этнографии, потому что долгое время данной проблеме исследователи не уделяли внимания. В середине ХХ века ученые акцентируют внимание на описании обрядов детского цикла, народном воспитании. Вопросы рождения и ухода за ребенком, его воспитания в этнокультурной и инокультурной среде сегодня не случайно занимают одно из центральных мест в изучении народов. Наша проблематика спроецирована на возрастной этап жизненного цикла (первый год жизни ребенка) армянского этноса, проживающего на территории города Самара. В статье рассматриваются две субэтнические группы (армяне из Республики Армения, «бакинские армяне») армянской общины, которые по-разному относятся к процессу воспитания детей. В работе представлен обобщающий материал по истории воспитания, традициям и обычаям первого года жизни армянского ребенка. В статье освещаются актуальные вопросы этнографической науки, связанные с протеканием беременности, рождением ребенка и его имянаречением, послеродовым периодом в жизни ребенка и роженицы, системой питания, одеждой и т.д.

Таким образом, изучение данного вопроса показало, что в некоторых аспектах культуры детства между двумя группами армян в Самаре существуют определенные различия, хотя и незначительные. «Бакинские армяне» более подвержены инокультурному и иноэтническому влиянию, что заметно в обрядах крестин, сказках, колыбельных и в выборе имени для ребенка.

Ключевые слова: армяне; семья; детство; имянаречение; родильная обрядность; воспитание детей; рождение ребенка; ритуалы; система питания; одежда; охранительные обычаи; обереги; инокультурная среда; этнография детства; Самара; этнос.

Тема детства на протяжении последнего столетия является одной из значимых в этнографической науке. Ей посвящены работы как зарубежных, так и российских ученых, таких, как Н.А. Бутинов [1], Г.А. Комарова [2, 3], Г.М. Науменко [4], Т. Стефаненко [5], В.Н. Харузина [6], М. Мид [7], Э. Эриксон [8]. Изучение мира детства можно разделить на несколько этапов. В дореволюционный период большое внимание уделялось описанию отдельных его характеристик, таких, как условия и обстановка родов, способы пеленания ребенка, форма, изготовления детской люльки, игры и т.д. В середине XX века ученые акцентируют внимание на описании обрядов детского цикла, народном воспитании. Уже в 80-е годы XX века И.С. Кон [9] и многие исследователи изучают вопросы социализации ребенка, подчеркивая их связь с традиционной системой воспитания народа. Отдельное место в их трудах отведено семейным и внесемейным институтам: например, школа, общество сверстников и средства массовой информации. В современных исследованиях детства этнологи выделяют детей как особое «сословие» [2, с. 84].

Вопросы рождения и ухода за ребенком, его воспитания в этнокультурной и инокультурной среде не случайно занимают одно из центральных мест в изучении народов. Для каждого народа в мире одной из главных целей является воспроизводство и дальнейшее развитие этноса. Армянский народ не является исключением - целью создания семьи для армян является рождение ребенка. Появление детей в доме - это счастье, уверенность в будущей жизни и беспечной старости, они составляют главное богатство и ценность для армянской культуры.

В данной статье будут рассматриваться некоторые аспекты этнографии детства армян, а именно обычаи, связанные с протеканием беременности, рождением ребенка, послеродовым периодом в жизни ребенка и роженицы, уходом за ребенком (пеленание, купание, кормление), некоторыми обрядами (крестины, празднование первого дня рождения, принцип имянаречения, а иногда выбор фамилии).

Вопросы этнографии детства армян затрагивались в ряде работ известных исследователей. Например, A.Е. Тер-Саркисянц [10] обращает внимание на празднование дня рождения, имянаречение и т.д. Ю.Ю. Антонян [11] описал способы, к которым армянки прибегали с целью забеременеть, родовспоможения и т.д. Статья Г.Бунятова [12] «Рождение, смерть, погребальные обычаи и представление о загробной жизни у армян Эриванской губернии» посвящена рождению ребенка, вопросам беременности и т.д. Указанные работы 